\title{
O ENSINO DE MATEMÁTICA PARA DEFICIENTES VISUAIS NAS ESCOLAS ESTADUAIS DE JANUÁRIA (MG)
}

\author{
TEACHING MATHEMATICS FOR VISUALLY DISABLED PEOPLE IN THE STATE \\ SCHOOLS OF JANUÁRIA (MG)
ENSEÑANZA DE MATEMÁTICAS PARA PERSONAS CON DISCAPACIDAD VISUAL EN LAS ESCUELAS ESTATALES DE JANUÁRIA (MG)

Josué Antunes de Macêdo

E-mail: josueama@gmail.com

\begin{abstract}
RESUMO
O presente trabalho aborda a discussão dos resultados de uma pesquisa, cujo objetivo foi analisar a situação do atendimento aos alunos deficientes visuais, em relação ao ensino de matemática, nas escolas públicas do município de Januária, situado no Estado de Minas Gerais. Trata-se de uma pesquisa qualitativa, em que realizou visitas às escolas, no qual foi possível identificar seis professores de matemática das séries finais do ensino fundamental e ensino médio que atuavam diretamente com alunos que possuem deficiência visual. Com o intuito de analisar algumas características relacionadas aos professores de matemática das escolas estaduais e da Superintendência Regional de Ensino de Januária, aplicou-se questionários estruturados para cinco dos seis professores e para uma servidora dessa superintendência, ao formar, assim, uma amostra com seis sujeitos. Foi possível analisar a concepção dos professores de matemática e da servidora quanto ao tema educação inclusiva. Como resultados obtidos, se verificou-se que todos os professores pesquisados não possuem curso de formação continuada na área de ensino de matemática para deficiente visual. Assim sendo, se conclui que o ensino dessa disciplina para deficientes visuais não se realiza de forma eficiente, uma vez que os docentes afirmaram não se sentirem preparados para lecionar para esses alunos.
\end{abstract}

PALAVRAS-CHAVE: Educação Inclusiva. Educação Matemática. Deficiência Visual. Materiais Manipulativos.

\section{ABSTRACT}

The present work addresses the discussion of the results of a research, whose objective was to analyze the situation of attendance to visually impaired students, in relation to the teaching of mathematics, in public schools in the municipality of Januária, located in the State of Minas Gerais. This is a qualitative research, in which visits were made to schools, in which it was possible to identify six mathematics teachers from the final grades of elementary and high schools who worked directly with students who have visual impairment. In order to analyze some characteristics related to mathematics teachers from state schools and the Januária Regional Teaching Superintendence, structured questionnaires were applied to five of the six teachers and to a servant of that superintendence, thus forming a sample of six subjects. It was possible to analyze the conception of mathematics teachers and civil servants regarding the theme of inclusive education. As results obtained, it was found that all teachers surveyed do not have a continuing education course in the area of teaching mathematics for the visually impaired. Therefore, it is concluded that the teaching of this subject for the visually impaired is not carried out efficiently, since the teachers stated that they do not feel prepared to teach these students.

KEYWORDS: Inclusive Education. Mathematical Education. Visual Impairment. Manipulative Materials.

\section{RESUMEN}

El presente trabajo aborda la discusión de los resultados de una investigación, cuyo objetivo fue analizar la situación de asistencia a estudiantes con discapacidad visual, en relación a la enseñanza de la matemática, en escuelas públicas del municipio de Januária, ubicado en el Estado de Minas. Gerais. Se trata de una investigación cualitativa, en la que se realizaron visitas a escuelas, en las que se logró identificar a seis profesores de matemáticas de los grados finales de primaria y secundaria que trabajaron directamente con estudiantes con 


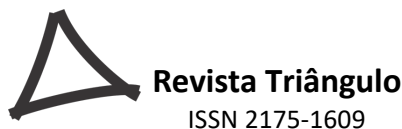

ISSN 2175-1609

discapacidad visual. Para analizar algunas características relacionadas con los docentes de matemáticas de las escuelas públicas y la Superintendencia Regional de Docencia de Januária, se aplicaron cuestionarios estructurados a cinco de los seis docentes y a un servidor de esa superintendencia, conformando asi una muestra de seis sujetos. Se pudo analizar la concepción de los profesores y funcionarios de matemáticas sobre el tema de la educación inclusiva. Como resultados obtenidos, se encontró que todos los docentes encuestados no cuentan con un curso de educación continua en el área de enseñanza de la matemática para personas con discapacidad visual. Por tanto, se concluye que la enseñanza de esta asignatura para personas con discapacidad visual no se lleva a cabo de manera eficiente, ya que los docentes manifestaron que no se sienten preparados para enseñar a estos estudiantes.

PALABRAS-CLAVE: Educación Inclusiva. Educación Matemática. Discapacidad Visual. Materiales Manipuladores.

\section{INTRODUÇÃO}

Ser educador, na atualidade, se insere em enfrentar desafios a cada dia e um desses desafios implica no ato de ensinar matemática para deficientes visuais. Por esse motivo surgiu a necessidade de discutir sobre educação inclusiva, tema significativo, uma vez que se trata de um assunto relevante ao convivo social e técnico.

Diante do exposto, se elaborou o presente trabalho, resultado de uma pesquisa desenvolvida nas escolas estaduais do munícipio de Januária, no Estado de Minas Gerais (MG) e na Superintendência Regional de Ensino (SRE) situados nessa cidade do Norte do estado de MG. Desse modo, a referida pesquisa divide-se em três etapas: inicialmente, se realizou os estudos bibliográficos sobre o tema abordado; em seguida, se deu a aplicação de questionários aos professores de matemática das séries finais do ensino fundamental, simultaneamente, para o ensino médio das escolas estaduais da cidade de Januária e para a Analista Referência de Educação Especial da SRE/Januária. Por fim se realizou a análise de dados coletados através dos questionários.

Discutir e pesquisar sobre o ensino de matemática para deficientes visuais torna-se importante, uma vez que esse consiste em ser um desafio para muitos professores, que possuem alunos com alguma deficiência em sua gestão de sala de aula. A curiosidade de estudar esse tema deu-se por experiências vivenciadas pela primeira autora durante a realização de atividades do Programa Institucional de Bolsa de Iniciação à Docência (PIBID) e observações realizadas durante a execução dos estágios curriculares obrigatórios do curso de Licenciatura em Matemática do Instituto Federal do Norte de Minas Gerais (IFNMG), Campus Januária.

Durante a realização das atividades, a primeira autora deste trabalho deparou-se com alunos que apresentavam deficiência visual, especificamente, a cegueira e junto com os professores regentes das turmas passaram por dificuldades para lidar com esses alunos, uma 
vez que ambos não possuíam nenhum conhecimento sobre como trabalhar com essas especificidades do alunado. Surgiu, então, a necessidade de analisar as condições dos professores de Matemática para trabalhar com alunos que apresentavam deficiência visual, consequentemente fez-lhe procurar metodologias condicentes a realidade desses alunos, tais como: materiais manipulativos que possam auxiliavam nesse ensino.

Nesse sentido, o objetivo deste trabalho foi analisar a situação do atendimento aos alunos deficientes visuais, quanto ao ensino de matemática, nas escolas estaduais de Januária (MG). O presente trabalho organiza-se em cinco seções, incluindo essa introdução. A segunda seção aborda o referencial teórico que sustenta as discussões deste trabalho. Na terceira, é descrita a metodologia utilizada para a realização desta pesquisa, a obtenção e análise de dados. $\mathrm{Na}$ quarta, se realiza a análise e a discussão dos dados coletados por meio dos questionários aplicados. Na quinta, se descreve as considerações finais do presente trabalho. Encerra-se este trabalho com as referências bibliográficas.

\section{REFERENCIAL TEÓRICO}

Ensinar matemática para deficiente visual é um desafio que alguns professores enfrentam em sala de aula. A falta de formação ou conhecimento de metodologias adequadas para trabalhar com alunos que apresentam algum tipo de deficiência, neste caso, cegueira, torna-se algo que dificulta ainda mais essa tarefa. Diante disso, se sabe que se torna necessário um profissional que estudara e entende dessa área de conhecimento. Por esse motivo, com o objetivo de auxiliar os docentes na execução dessa tarefa, várias pesquisas foram realizadas, dentre elas, cita-se Souza (2005), Victoriano (2010), Silva, Carvalho e Pessoa (2016), Martins e Bianchini (2017), entre outros.

Segundo Vieira e Silva (2007), a matemática sempre foi vista pelos alunos como uma das disciplinas mais difíceis, presentes no currículo escolar. Quando se pensa em educação inclusiva, a situação torna-se ainda mais delicada, pois os alunos com deficiência sofrem com a falta de preparo dos profissionais da educação, no qual em muitos casos não sabem lecionar para esses alunos por falta de conhecimentos específicos. Isso decorre da necessidade de utilização de recursos metodológicos. Quando se trata especificamente da deficiência visual o professor usa-se uma metodologia no qual a visão não seja um dos principais meios para troca de informações. 


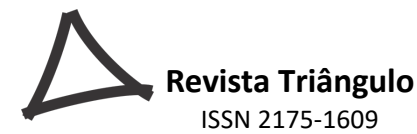

Para aprimorar o ensino destinado a pessoas com deficiência, Casatti e Castelli (2014), relatam que a professora Edna Zuffi, do Instituto de Ciências Matemáticas e de Comunicação (ICMC) da Universidade de São Paulo (USP), em São Carlos, destacou que o primeiro passo implica em garantir o acesso a informação. O professor ao conhecer a lei vigente passa a conhecer quais recursos o governo oferece, e os locais onde é possível conseguir materiais que se utiliza no ensino desses alunos.

Casatti e Castelli (2014), ressaltaram que há uma ação interessante realizada no ICMC da USP, em São Carlos. Desde 2012, porque os alunos do curso de licenciatura em matemática podem-se matricular em uma disciplina optativa com foco na preparação do licenciado para desenvolver o conteúdo escolar de matemática em relação aos alunos com deficiência. Assim, ao cursar a disciplina, os futuros professores têm a oportunidade de examinar a literatura e legislação disponíveis sobre a temática da inclusão escolar, simultaneamente, relacioná-la com as questões específicas de ensino e aprendizagem de matemática nos níveis fundamental e médio.

Segundo Barbosa (2003), a busca por recursos adequados para trabalhar com alunos que possuem deficiência visual, exigia do professor uma visão além da deficiência, à medida que se ressalta nas peculiaridades e limitações do aprendizado de cada criança, seja ela vidente ou não.

$\mathrm{Na}$ atualidade, se sabe que para os deficientes visuais, o tato torna-se um sentido importante, pois através dele fica possível que essas pessoas compreendam: formas, tamanhos, texturas, entre outros. Sendo assim, se observa a necessidade de materiais manipuláveis no ensino de matemática para alunos com essa deficiência.

Antes de ministrar as suas aulas, evidenciando aqui as aulas de matemática, se destaca a importância de que os professores atentem para alguns quesitos relevantes, que ajudam a obter um resultado mais eficiente em relação ao processo de ensino e aprendizagem dessa disciplina para haver entendimento, e compreensão do conteúdo pelos alunos.

Para o aluno ter compreensão do ensino de matemática, se faz necessário que o professor utilize uma didática no qual o aluno possa participar das discussões dos conteúdos ministrados a cada aula. Sendo assim, as pesquisas desenvolvidas por Victoriano (2010), Martins e Bianchini (2017), apontaram que o uso de materiais manipuláveis consiste em ser fundamental no ensino de matemática, pois este artifício ofereceu ao aluno uma maneira diferenciada de compreender essa ciência. 
Segundo Brasil (2005), o ensino da matemática voltado apenas em exposições teóricas, sem experiência concreta e significativa torna a aula infecunda, porque não conta com a participação do aluno por falta de recursos didáticos adequados. Diante disso, se evidencia a dificuldade do alunado para compreender o que se ensina em espaços escolares.

Segundo Dante (2005), o professor deve criar oportunidades que possibilitariam ao aluno utilizar materiais manipuláveis, diz ainda que a abstração de ideias teriam a sua origem na manipulação e atividades mentais a ela associadas. Nessa consonância, se entende que o aluno com deficiência visual,

[...] geralmente adquirem seu conhecimento por meio de experiências que não incluem o uso da visão, faz-se necessário que lhes sejam oferecidas oportunidades para desenvolver os sentidos remanescentes: tato, audição, olfato e mesmo paladar (BRASIL, 2005, p. 46).

Desse modo, se entende que trabalhar matemática com aluno deficiente visual exige a utilização de materiais concretos, uma vez que é por meio do tato que o aluno apreende. Logo, essa ação constitui em ser primordial quando se trata desta deficiência.

\section{MÉTODOS}

Segundo Gil (2008), toda e qualquer pesquisa classifica-se com base em seus objetivos e procedimentos técnicos. Com base nos objetivos da presente pesquisa, de acordo com o autor acima citado esta pesquisa classifica-se como exploratória e descritiva.

De acordo com Gil (2002), a pesquisa exploratória tem como objetivo principal proporcionar maior familiaridade com o problema, ao buscar, assim, torná-lo mais explícito. $\mathrm{Na}$ maioria dos casos, essas pesquisas envolvem levantamento bibliográfico e entrevistas com pessoas que estejam por dentro do assunto abordado. Fiorentini e Lorenzato (2007) afirmaram que pesquisa exploratória caracteriza-se por meio de estudos que buscam melhor esclarecimento sobre o assunto abordado, para isso se faz necessário o uso de estudos bibliográficos, ou até mesmo aplicação de questionários e estudo de casos.

Em relação à pesquisa descritiva, Gil (2008) classifica-a como aquela que tem como objetivo primordial a descrição das características de determinada população, fenômeno ou estabelecimento de relações entre variáveis. São inúmeros os estudos que foram classificados sob este título e uma de suas características mais significativas situa-se na utilização de técnicas padronizadas de coleta de dados. 


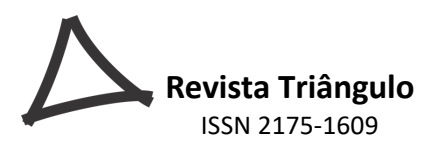

Outro objetivo importante na realização do presente trabalho, foi analisar algumas características relacionadas aos professores de matemática das séries finais do ensino fundamental e ensino médio das escolas estaduais da cidade de Januária, Minas Gerais, quanto ao ensino de matemática para deficientes visuais, bem como averiguar quais os suportes que a SRE de Januária oferecia aos professores e alunos. Para isso foi utilizado aplicação de questionários aos professores e a servidora da SRE de Januária. Nesse sentido, Gil (2008, p. 121) definiu questionário como:

[...] a técnica de investigação composta por um conjunto de questões que são submetidas a pessoas com o propósito de obter informações sobre conhecimentos, crenças, sentimentos, valores, interesse, expectativas, aspirações, temores, comportamento, presente ou passado, etc.

Vale ressaltar que a presente pesquisa é de cunho qualitativo, uma vez que Gil (2002), afirmou que a análise qualitativa depende de muitos fatores, tais como: natureza dos dados coletados, extensão da amostra, instrumentos de pesquisa e pressupostos teóricos que nortearam a investigação. Pode-se, no entanto, definir esse processo como uma sequência de atividades, que envolve a redução dos dados, a categorização desses dados, sua interpretação e a redação do relatório.

\section{Sujeitos da Pesquisa}

Os sujeitos pesquisados tiveram como foco um funcionário da SRE de Januária e os professores que na época lecionavam matemática, para alunos com deficiência visual matriculados nas séries finais do ensino fundamental e/ou ensino médio, das escolas estaduais de Januária (MG).

Após analisados os dados fornecidos pela SRE de Januária e visitas realizadas às escolas, foi possível identificar seis professores de matemática dos anos finais do ensino fundamental e do ensino médio (ambos de escolas estaduais desse município) que lecionavam para deficientes visuais. Após contato com esses professores realiza-se a aplicação de questionários para todos eles e desses apenas um não devolveu o questionário. Sendo assim, a amostragem foi composta por seis sujeitos, cinco professores e uma servidora da SRE de Januária. 
Vale ressaltar que na época da realização da pesquisa, haviam seis alunos com deficiência visual matriculado nas séries finais do ensino fundamental ou ensino médio das escolas estaduais da cidade de Januária. Cada aluno estava matriculado em uma escola e o professor de matemática era diferente. Na sede do município há um total de nove escolas estaduais da cidade que ofertavam as séries finais do ensino fundamental e/ ou ensino médio, seis delas possuíam matrícula de aluno com deficiência visual.

\section{RESULTADOS E DISCUSSÃO}

Os dados apresentados e discutidos nesta seção são resultados dos questionários aplicados aos professores de matemática das séries finais do ensino fundamental e/ou do ensino médio das escolas estaduais da cidade de Januária (MG), no qual estavam lecionando para alunos com deficiência visual. Em seguida, se discutirá as respostas obtidas através do questionário aplicado ao funcionário da SRE de Januária.

\section{Análise e Discussão dos Questionários Aplicado aos Professores}

A seguir, serão expostas as questões presentes no questionário e discutida as respostas apresentadas pelos professores.

A primeira questão teve a intenção de verificar o tempo de experiência dos professores na docência. Nesse sentido, eles foram indagados: Há quanto tempo você leciona a disciplina de matemática?

Os cinco professores pesquisados, aqui chamados de A, B, C, D e E, lecionam há cinco, sete, quatorze, dezessete e vinte e quatro anos, respectivamente. Desses, o primeiro (A) e o terceiro (C) lecionam para alunos cegos. Os demais para alunos com baixa visão. Assim, se salienta que o tempo de experiência na docência, contribui para que os professores adquiriram experiência e vivência para lecionar aos alunos com deficiência visual.

A segunda questão teve como objetivo analisar a perspectiva desses professores quando se trata de inclusão de alunos com deficiência visual em salas regulares. Assim, eles foram indagados: Como você vê a política de inclusão dos deficientes visuais nas escolas da rede pública?

Analisando as cinco respostas obtidas nessa questão, se conclui que os professores foram unânimes em afirmar que a inclusão existe, mas de forma incipiente, porque o estado 
insere os alunos na escola, mas, não oferece suporte aos alunos e professores. Desse modo, se expõe algumas respostas obtidas nessa questão:

Muito complicada por que não tivemos capacitações, então encontramos muita dificuldade para trabalhar com esses alunos e criar atividades diferenciadas. Na realidade o estado insere o aluno nas escolas sem saber se a mesma possui suporte que atenda às necessidades desse aluno (Professor A).

A inclusão existe, porém não acontece de forma que possa atender com clareza as necessidades apresentadas pelos alunos e professores. Ainda faltam recursos, capacitação e adequação a realidade de cada aluno. Posso afirmar que a inclusão de fato ainda não acontece, pois, os alunos são apenas inseridos nas escolas (Professor E).

Ao afirmar que a inclusão existe de forma incipiente, se conclui que as falas dos professores estão em comum, de acordo com Mittler (2003), no qual afirmou que a inclusão educacional visa todo um processo de mudança e reestruturação das escolas, no qual o objetivo principal ao incluir alunos deficientes em uma escola regular assegura que esses teriam acesso a todas as atividades sociais e educacionais que a escola oferece. Seguindo essa definição e ao analisar as respostas dos professores, se constata que a educação inclusiva não se realiza de forma totalmente favorável, uma vez que os professores não inserem os alunos em todas as atividades oferecidas em sala de aula.

A próxima questão aplicada foi: Você já lecionou ou leciona para aluno com alguma deficiência visual?.

Nessa questão os professores A e C relataram que trabalham com alunos cegos e os professores B, D e E responderam que atualmente trabalham com alunos que apresentam baixa visão.

A quarta questão procurou investigar a formação dos professores para lidarem com alunos deficientes visuais: Você possui cursos de capacitação e formação continuada que contemple metodologias de ensino direcionadas aos alunos com deficiência visual? Caso positivo especifique-os.

Dos cinco professores entrevistados, todos afirmaram não possuir formação para trabalhar com alunos que possuem deficiência visual.

Sendo assim, a falta de formação citada pelos professores torna-se algo que merece ser discutida. Uma vez que, no estado de Minas Gerais, o Núcleo de Capacitação e Apoio Pedagógico às Escolas de Educação Básica tem entre seus objetivos: 
- Promover, ministrar e avaliar capacitação e orientação didáticopedagógica para professores da rede pública que atendem estudantes com deficiência visual e surdocegueira;

- Orientar, didática e pedagogicamente, as escolas que possuem estudantes com deficiência visual e surdocegueira

- Realizar visitas ás escolas estaduais que tenham estudantes cegos e com baixa visão para orientar e acompanhar o trabalho da equipe, em função da efetiva inclusão dos estudantes (MINAS GERAIS, 2017, p. 8).

Vale ressaltar que a cidade de Januária possuí esse Núcleo de Capacitação e Apoio às Escolas de Educação Básica, sendo assim, surgiu, aqui, um problema para possível investigação em pesquisas futuras. Como é feito a divulgação dos cursos de formações oferecida pelos núcleos? Qual método de seleção dos professores para participarem de tal curso?

Com relação à metodologia utilizada em sala de aula com os alunos deficientes visuais, indagou-se: Qual metodologia você utiliza para trabalhar com os alunos deficientes visuais?

Nessa questão as respostas dos professores B, C e D, foram semelhantes. Ambos afirmaram não possuir metodologia específica para trabalhar com alunos que apresentavam deficiência visual:

A deficiência do meu aluno é baixa visão, mas até então não o atrapalha no desenvolver das atividades normais da turma. Sendo assim a metodologia utilizada é a mesma que utilizo com a turma. Mas confesso que caso essa deficiência venha evoluir, ou apareça casos de alunos com essa deficiência e que necessite de uma metodologia diferenciada acredito que terei muita dificuldade para lidar com essa situação e será realmente um desafio (Professor B).

Comecei a trabalhar nessa escola há poucos meses, sendo assim ainda não estabeleci uma metodologia para trabalhar com ela. Confesso que será um pouco difícil, pois essa é a minha primeira experiência com aluno cego (Professor C).

Não tenho uma metodologia específica para ele, utilizo a mesma que utilizo com a turma, algumas atividades ele desenvolve só, outras peço para sentar com algum colega (Professor D).

Observa-se aqui a dificuldade que os professores têm para trabalhar com alunos que possuem deficiência visual. Percebe-se que os alunos não participam efetivamente das aulas, uma vez que a metodologia utilizada pelos professores não era específica para trabalhar com alunos com tal deficiência.

Os professores A e E afirmaram utilizar algum tipo de metodologia, mas analisando-as, se conclui que o aluno não estava totalmente inserido nas atividades propostas. Como: 
Apenas algumas atividades orais. Normalmente peço para a aluna bolsista do Pibid auxilia-la nas atividades, e isso tem me ajudado bastante (Professor A)

Aulas práticas voltadas para o cotidiano e utilização de materiais táteis (Professor E).

Quanto à preparação para ensinar matemática para deficientes visuais, os docentes foram indagados: Você se sente preparado(a) para ensinar matemática para deficientes visuais? Justifique.

Nessa questão os professores foram unânimes, ao afirmar que não se sentem preparados para trabalhar com esses alunos, uma vez que não possuem nenhuma formação especializada e não tem conhecimento sobre metodologias específicas que eram utilizadas para trabalhar com esses alunos.

Percebe-se que essa situação é um problema que persiste, pois na pesquisa realizada por Manrique e Ferreira (2010), foi constatada que a maior reclamação dos professores pesquisados era a falta de capacitação como processo facilitador para lidar com essa questão.

Na sétima questão, se procura saber se os docentes conheciam materiais manipulativos possíveis de serem utilizados no ensino de matemática. Nesse sentido, eles foram indagados: Você tem conhecimento de materiais manipulativos que possam facilitar o ensino de matemática para deficientes visuais? Caso positivo especifique-os.

O Professor E, disse:

Sim, conheço o material dourado, blocos lógicos e sólidos geométricos. Há um tempo pesquisei algumas atividades diferenciadas para trabalhar com o meu aluno e acabei lendo sobre esses três materiais. Utilizei apenas os sólidos geométricos no ensino de geometria.

Os demais professores afirmaram não ter conhecimento de nenhum material manipulativo que possa auxiliar no ensino de matemática para deficiente visual.

O fato de os professores não terem conhecimentos sobre materiais manipulativos para ensino de matemática insere-se em ser algo preocupante, uma vez que segundo Dante (2005), o professor criou oportunidades que possibilitariam ao aluno utilizar materiais manipuláveis, pois a abstração de ideias tem sua origem na manipulação e atividades mentais a elas associadas.

Na questão oito, indagou-se: No seu ponto de vista como professor(a), o que poderia ser feito para facilitar o ensino de matemática para deficientes visuais? 
Os professores foram unânimes em afirmar que a principal maneira de facilitar esse ensino, seria oferecendo aos professores capacitações especializadas. Essa fala está de acordo com Mantoan, Pietro e Arantes (2006), nos quais afirmaram que o sistema educacional devese comprometer com essa formação e assim, estará a melhorar a qualidade do ensino. Desse modo, se assegura que esses professores sejam aptos a elaborar e implantar novas propostas, simultaneamente, as práticas de ensino para responder as necessidades dos alunos com deficiência.

\section{Questionário Aplicado a Servidora da SRE da Cidade de Januária}

Expor-se-á nesta seção as questões presentes no questionário e as respostas obtidas. A primeira questão teve a intenção de verificar quais as políticas públicas vinculadas à inclusão educacional que o estado de Minas Gerais possui. Nesse sentido, indagou-se: Quais as políticas públicas que o estado possui para inclusão de deficientes visuais em escolas regulares?

O primeiro passo é a política pública do direito a matrícula nas escolas da rede pública ou privada; Em seguida é o direito a outra matrícula no sistema SIMADE (Sistema Mineiro de Administração Escolar) no AEE- (Atendimento Educacional Especializado) para aprender o braile, também tem direito a receber notebook e kits para cegos.

A resposta obtida pela servidora da SRE está de acordo com os dados informados por Minas Gerais (2017), uma vez que este documento afirmou realmente a existência das políticas públicas citadas.

A segunda questão teve como objetivo averiguar a contribuição da SRE na oferta de materiais especializados para alunos com deficiência visual. Para isso, foi questionado o seguinte: A Superintendência Regional de Ensino de Januária dispõe de serviços de impressão em braile e de confecção de outros materiais didáticos pedagógicos direcionados para alunos com deficiência visual? Em caso positivo especifique-os. A servidora respondeu o seguinte:

Na SRE especificamente não, mas é feita toda solicitação para os encaminhamentos dos kits e equipamentos para a AEE- Sala de Recursos onde muitas delas já têm máquinas em braile, impressora em braile, notebooks adaptados e muitos materiais e jogos pedagógicos educativos, ou seja, que contemplam os conteúdos acadêmicos e todos em braile, como também aumentativo e adaptados para a baixa visão. 
Nessa questão não foi possível analisar com aprofundamento a resposta obtida, uma vez que a servidora disse que a SRE especificamente não oferece todo suporte pedagógico aos alunos com deficiência visual, mas afirma ter solicitado tais materiais, mas não deixou claro a quem foi realizado essa solicitação.

Com o objetivo de analisar a quantidade de alunos com deficiência visual nas escolas estaduais de Januária, foi questionado o seguinte: Atualmente qual o número de alunos com deficiência visual matriculados nas escolas regulares da cidade de Januária? Desse total, quantos são das escolas públicas?

Esses dados são somente do município sede de Januária, dos estudantes que estão matriculados e frequentes: 14 estudantes com baixa visão e 4 com cegueira.

Ao observar os dados propostos, a servidora da SRE afirmou que existiam dezoito alunos com deficiência visual matriculados em escolas estaduais na Zona Urbana da cidade de Januária.

A quarta questão visa averiguar a existência ou não, de escolas especializadas na cidade de Januária, para isso foi feito o seguinte questionamento: Na cidade de Januária existe escola destinada especialmente para alunos com deficiência visual? Caso positivo cite-as.

Não, porque com a premissa da lei da inclusão os alunos com cegueira ou baixa visão deverão todos serem incluídos nas escolas públicas ou privadas.

Observa-se nesse fragmento que houve um avanço no processo de inclusão, uma vez que alunos com deficiência visual foram inseridos em escolas regulares. De acordo com Minas Gerais (2017), em setembro de 2016, os dados do Sistema Mineiro de Administração Escolar (SIMADE) indicaram que o Estado de Minas Gerais possuía 3.112 (três mil, cento e doze) estudantes com baixa visão, 315 (trezentos e quinze) cegos e 13 (treze) surdocegos matriculados nos diversos municípios mineiros, atendidos no Ensino Fundamental e no ensino médio.

Com relação a oferta de cursos de formação para professores, foi feito o seguinte questionamento: A secretaria Estadual de Educação disponibiliza cursos de capacitação e formação continuada para os professores da rede pública, que contemple metodologias de ensino direcionadas aos alunos portadores de deficiência visual? Caso exista, como são selecionados esses professores? 
Sim, a formação dos profissionais é outra politica pública do estado. Com muita luta a SRE de Januária conquistou para toda a sua área de abrangência (19 municipios) um Núcleo de capacitação nas áreas visual e surdez, onde os profissionais $1^{\circ}$ das AEE- sala de recursos e professores da sala comum são capacitados.

Essa resposta traz certo questionamento, uma vez que os cinco professores pesquisados afirmaram não possuírem curso de formação, logo como é feito a divulgação e seleção de professores para o referido curso? Este questionamento foi feito na presente questão, mas não se obteve uma resposta.

Na sexta questão foi feito os seguintes questionamentos: Quanto aos Centros de Apoio Pedagógico às Pessoas com Deficiência Visual (CAP) e aos Núcleos de Capacitação de profissionais na área da deficiência visual:

a) Quantos CAP e núcleos a Secretaria Estadual de Educação de Minas Gerais mantém em funcionamento atualmente? Obtendo como resposta:

São cinco CAPS e dois núcleos em todo o estado de $M G$.

b) Em quais municípios esses CAP estão localizados? Cuja resposta foi a seguinte:

CAPS São Rafael (BH), Montes Claros, Patos de Minas, Uberaba, Três Corações.

Núcleos: Januária e Governador Valadares.

C) Quando necessário, os professores da SRE de Januária recorrem a qual CAP? A servidora disse o seguinte:

O Núcleo de Capacitação da SRE de Januária é subordinado ao CAP/Montes Claros e Todas as ações do Núcleo são articuladas com o CAP.

As respostas obtidas nessa questão estão de acordo com os dados disponibilizados por Minas Gerais (2017), uma vez que neste documento citava a existência de tais CAP e Núcleos. Diante disso, se tem o intuito de analisar o ponto de vista da SRE quando se trata de inclusão educacional, foi feito o seguinte questionamento: Como você vê a política de inclusão dos deficientes visuais nas escolas da rede pública? A servidora respondeu:

De uma forma muito positiva, pois perante as legislações é a garantia do estado de direito dos estudantes com deficiência visual. Porém ainda há algumas mazelas na prática, as vezes do próprio sistema, desde a união da falta de alguns materiais e equipamentos disponiveis a todo o nosso AEESala de Recursos, como também os Kits para cegos e baixa visão. Mas a SRE busca constantemente a efetivação dos direitos dos estudantes com 


\section{Revista Triângulo

deficiência visual como também das outras deficiências primando assim as legislações estaduais, nacionais e internacionais.

Desse modo, se conclui que há uma colocação positiva da SRE ao tratar de inclusão educacional e isto diverge das respostas obtidas na questão direcionada aos professores abordando a educação inclusiva, uma vez que esses afirmaram que a inclusão educacional era realizada de forma incipiente.

\section{Relacionando os Dados Obtidos nos Questionários Aplicado aos Professores e a Servidora da Superintendência de Januária}

Ao comparar as respostas obtidas através dos questionários aplicados aos professores e a servidora da SRE, conclui-se que há algumas observações que merecem ser destacadas. A principal delas foi quando se trata sobre o curso de capacitação e formação continuada para os professores que lecionam para deficientes visuais.

A questão em destaque é que todos dos professores pesquisados afirmam não possuírem capacitação e formação para trabalhar com deficientes visuais, até citam como ação que melhora o ensino de matemática para deficiente visual a oferta de cursos de capacitação e formação voltada para esse ensino.

A servidora da SRE, afirmou que a formação dos profissionais é uma das políticas públicas do estado e que a SRE de Januária oferecia cursos de capacitações para professores ao abordar o ensino para alunos com deficiência visual.

Ao comparar as duas respostas obtidas, se supôs que não há divulgação dos cursos ofertados ou essa divulgação é feita de forma incipiente, uma vez que a SRE afirmou ofertar tal curso e os professores demonstraram não terem nenhum conhecimento sobre a sua existência.

Outra observação que merece destaque foi quanto ao número de alunos com deficiência visual matriculados nas escolas regulares da sede de Januária. A servidora da SRE de Januária afirmou que existia um total de dezoito alunos com deficiência visual matriculados em escolas regulares na zona urbana da cidade. Após visita realizada às escolas, se constata que existiam apenas seis alunos com deficiência visual matriculados nas séries finais do ensino fundamental ou no ensino médio dessas escolas estaduais. 


\section{CONSIDERAÇÕES FINAIS}

Este trabalho teve como objetivo analisar a situação do atendimento aos alunos deficientes visuais, quanto ao ensino de matemática nas escolas estaduais de Januária. Após a realização da pesquisa, se conclui que o ensino de matemática para deficiente visual nessas escolas estaduais da cidade, não se realizava de forma satisfatória, uma vez que os professores pesquisados afirmaram não terem formação para lidar com a inclusão, e não possuir conhecimento de metodologias específicas que utilizavam no ensino de matemática para deficientes visuais.

Todos os professores pesquisados afirmaram não utilizarem materiais manipulativos em suas aulas e não veem a política de inclusão como algo realizado com êxito. Diante disso, se observa que não há um ensino de matemática com qualidade para deficientes visuais nas escolas estaduais de Januária, pois as aulas voltavam especificamente para videntes e aos alunos que possuem deficiência visual passivamente participam das atividades proposta pelo professor.

De acordo com as respostas obtidas pelos professores, se observa que esses afirmaram como principal fator que contribui para defasagem no ensino de matemática para deficiente visual, a falta de formação específica apresentada pelos próprios professores, ainda asseveraram que o estado não oferece suporte para que possam proporcionar aos alunos com deficiência visual um ensino de qualidade.

Embora, o governo discuta inclusão educacional como algo tão perfeito, pode se ver que essa não é a realidade encontrada nas escolas estaduais na cidade de Januária. Vale destacar que ao analisar as políticas públicas oferecidas pelo estado quando se trata de educação inclusiva, a única ação que realmente está em vigor é o direito do aluno à matrícula em escola regular e, assim, se conclui que o estado preocupa mais com dados quantitativos do que qualitativos.

Observa-se que os números de matrículas de alunos com deficiência visual em escolas regulares aumentam a cada dia, logo ações serão tomadas para que ocorra, de fato, a inclusão desses alunos em escolas regulares, ao oferecê-los um ensino de qualidade com professores especializados e materiais manipulativos para auxiliar na absorção de conhecimentos.

\section{REFERÊNCIAS}

BARBOSA, Paula Marcia. O estudo da geometria. Revista Instituto Benjamin Constant. 25 ed. artigo 3, Ago. 2003. Disponível em: 


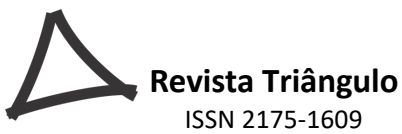

http://www.ibc.gov.br/images/conteudo/revistas/benjamin constant/2003/edicao-25agosto/Nossos_Meios_RBC_RevAgo2003_Artigo_3.pdf. Acesso em 29 ago. 2021.

BRASIL. Saberes e prática da inclusão: Desenvolvendo Competências para o atendimento às necessidades educacionais especiais de alunos cegos e de alunos de baixa visão. Brasília: MEC/SEESP, 2005.

CASATTI, Denise; CASTELLI, Ronaldo. Ensino de matemática para pessoas com deficiências. Portal Brasil. Dez, 2014. Disponível em: http://www.usp.br/agen/?p=195344. Acesso em: 29 ago. 2021.

DANTE, Luiz Roberto. Didática da resolução de problemas de matemática. 12. ed. São Paulo, 2005.

FIORENTINI, Dario; LORENZATO, Sérgio. Investigação em educação matemática: percursos teóricos e metodológicos. 2. ed. Campinas: Autores Associados, 2007.

GIL, Antônio Carlos. Como elaborar projetos de pesquisa. 4. ed. São Paulo: Atlas, 2002.

GIL, Antônio Carlos. Métodos e técnicas de pesquisa social. 6. ed. São Paulo: Atlas, 2008.

MANRIQUE, Ana Lúcia; FERREIRA, Guilherme Lazarini. Mediadores e mediação: A inclusão em aulas de matemática. Revista contrapontos, v.10, n. 1, 2010. Disponível em: https://siaiap32.univali.br/seer/index.php/rc/article/view/2110. Acesso em 29 ago. 2021.

MANTOAN, Maria Teresa Eglér; PRIETO, Rosângela Gavioli; ARANTES, Valéria Amorim (org.). Inclusão escolar: Pontos e Contrapontos. 1 ed. São Paulo: Summus, 2006.

MARTINS, Elen Graciele; BIANCHINI, Bárbara Lutaif. A matemática e a pessoa cega: um breve panorama das pesquisas realizadas no Brasil entre 2010 e 2015. Revista de Produção Discente em Educação Matemática. São Paulo. v. 6, n. 1, 2017. Disponível em: https://revistas.pucsp.br/index.php/pdemat/article/view/32590. Acesso em 29 ago. 2021.

MINAS GERAIS. Centro de apoio pedagógico às pessoas com deficiência visual (CAP): Histórico e diretrizes de funcionamento. Belo Horizonte: Secretaria de estado de educação de Minas Gerais, 2017.

MITTLER, Peter. Educação inclusiva: Contextos sociais. 1 ed. Porto Alegre: Artmed, 2003.

SILVA, Mayra Darly; CARVALHO, Liliane Maria Teixeira Lima de; PESSOA, Cristiane Azevêdo dos Santos. Material manipulável de geometria para estudantes cegos: reflexões de professores brailistas. Revista Paranaense De Educação Matemática. v. 5, n. 9, p. 176-202, jul/dez. 2016. Disponível em: http://revista.unespar.edu.br/index.php/rpem/article/view/497. Acesso em 29 ago. 2021.

SOUZA, Talya da Silva Warmling de. Como trabalhar o ensino da matemática com o Educando cego e a inclusão dos mesmos em classes regulares. 2005. MonografiaUniversidade do Extremo Sul Catarinense- UNESC, Santa Catarina. 
VICTORIANO, Gilson do Nascimento Gouvêa. Didática e materiais concretos no ensino da geometria: A perspectiva de quem não vê. 2010, 80 f. Dissertação (Mestrado) Universidade Severino Sombra, Pró-Reitoria de Pesquisa e Pós-Graduação, programa de PósGraduação Stricto Sensu Mestrado Profissional em Educação Matemática, Vassouras- RJ, 2010 .

VIEIRA, Silvio Santiago; SILVA, Francisco Hermes Santos da. Flexibilizando a geometria na educação inclusiva dos deficientes visuais: uma proposta de atividades. In: ENCONTRO NACIONAL DE EDUCAÇÃO MATEMÁTICA, 9, 2007. BELO HORIZONTE: SBEM, 2007. Anais... Belo Horizonte, 2007. 